\title{
Reseña de Vinatea, Martina, «Fundación y grandezas de la muy noble y muy leal ciudad de los Reyes de Lima» de Rodrigo de Valdés. Estudio y edición crítica, Nueva York, IDEA, 2018, 352 pp. ISBN: 978-1-938795-46-6
}

\section{Fernando Rodríguez Mansilla}

Hobart and William Smith Colleges, Geneva, New York ESTADOS UNIDOS

Mansilla@hws.edu

[Hipogrifo, (issn: 2328-1308), 6.2, 2018, pp. 837-840]

Recibido: 17-10-2018/ Aceptado: 24-10-2018

DOI: http://dx.doi.org/10.13035/H.2018.06.02.59

Este libro consiste en el estudio y edición del singular poema Fundación y grandezas de la muy noble y muy leal ciudad de los Reyes de Lima, compuesto por el jesuita limeño Rodrigo de Valdés (1609-1682) y publicado póstumamente en Madrid en 1687. Se trata de un complejo proyecto literario con un doble propósito: por un lado, desarrollar un discurso corográfico de la ciudad de Lima, cuyos principales episodios históricos se recrean, de la mano de sus personajes más eminentes; por otro, brindar un texto que sirva como herramienta pedagógica para el príncipe (futuro Carlos II), ya que Valdés practica un lenguaje poético que engarza el latín y el español.

El estudio preliminar de Martina Vinatea ofrece al lector todos los materiales necesarios para comprender los alcances del poema, sus principales características y buena parte de los contenidos que expone Valdés en su alambicada expresión lírica. La editora hace un repaso de los personajes históricos aludidos, así como de sus principales obras. Entre estos, junto a virreyes y arzobispos, destacan los dos personajes eje del poema: Francisco Pizarro, como fundador de la ciudad que se describe, y Santa Rosa de Lima, santa recientemente canonizada (1671, dieciséis años antes de la publicación del poema), ejemplo máximo del fervor religioso limeño y de los frutos de la evangelización en América. Igualmente, la editora plantea una forma de leer el poema: entendiéndolo como un texto que reivindica a los criollos, los dota de una identidad y de una historia propia alrededor de la construcción de Lima, centro de poder virreinal, y las figuras emblemáticas que vivieron en ella, empezando por su fundador, Francisco Pizarro. Fundación y grandezas se inserta, 
así, en la literatura colonial de exaltación de la causa criolla en el contexto de su competencia con los peninsulares en torno a la hegemonía política y económica dentro del Nuevo Mundo. La orden jesuita, a la que pertenecía su autor, no era ajena a esta agenda y es comprensible que el talento de Valdés contase con el apoyo de la Compañía para realizar una eminente carrera tanto religiosa como intelectual en Lima. Rodrigo de Valdés, en ese sentido, es un intelectual criollo modélico, proveniente de una familia prestigiosa en la Lima de entonces, con vínculos sólidos en la península (como que se hallaba emparentado con el virrey marqués de Montesclaros).

Con tan rico contenido en torno a la ciudad de Lima, el poema se propone también como un ejercicio de genealogía, una rama de la escritura historiográfica que se adaptaba bien a la forma poética, considerando que esta le brindaba un estilo elevado, el cual transmitiría formalmente la nobleza que se pretendía para la ciudad celebrada. Junto a su alcurnia, Lima destaca, dentro del discurso de Valdés, por su lealtad. Dicha lealtad se comprende tanto por su vínculo estrecho con la Corona como por su catolicismo, que se consagra con la figura de la reciente santa local. Esta representación de la ciudad es indesligable de la perspectiva criolla que se asume: en el recuento de la historia, las tradiciones y los personajes insignes de Lima aflora un orgullo local en el que confluyen la constante asociación con un legado peninsular (a través de la historia, los linajes y los proyectos político-religiosos) y la celebración del aprovechamiento de recursos naturales nativos (en primer lugar, metales preciosos, pero también productos agrícolas) que se consideran la contribución principal del virreinato a la maquinaria del vasto imperio español.

En términos formales, el poema se compone de 571 cuartetas de ocho sílabas, en 38 cantos, que el autor denomina «párrafos». La originalidad del proyecto pone en primer plano el lenguaje empleado, ya que Fundación y grandezas es una muestra de poesía hispanolatina, un género lírico que tuvo corta vida y pocos ejemplos durante el Siglo de Oro. Este tipo de poesía consiste en aprovechar la cercanía del latín con el español para usar la mayor cantidad de palabras semejantes en ambos idiomas. La idea detrás de este ejercicio bebe del imperialismo español del Siglo de Oro: parangonar el castellano o español con el latín era otra forma, simbólica, de translatio imperii. Si a ello se añade que Rodrigo de Valdés es criollo y exalta su patria, a la que igualmente engrandece con su poema corográfico, la elaborada lengua poética de la Fundación y grandezas encierra también un propósito de defensa de la intelectualidad criolla frente a los prejuicios del Viejo Mundo, donde se veía con sospecha la capacidad de los americanos de adquirir y producir conocimiento. De hecho, según lo comenta Martina Vinatea en su reseña del género hispanolatino en la poesía aurisecular, Fundación y grandezas ocupa un lugar destacado entre las composiciones que mezclaron el español y el latín, por su extensión y la complejidad de su diseño temático.

Una forma sencilla de caracterizar el poema es, como lo hace un crítico decimonónico, considerarlo una «crónica rimada». En efecto, la estructura del poema aspira a capturar tanto el espacio urbano, que se va a celebrar, como la historia de la ciudad, sus principales hechos y las acciones destacadas de sus personajes, es decir interseca lugares y tiempos diferentes: empieza con un paseo del pendón real 
por la plaza de armas de la capital, pasa a relatar la conquista del Perú y prosigue el desarrollo cronológico de Lima hasta llegar a Santa Rosa, la santa local, a la que, explotando su nombre, se identifica como la flor más perfecta del jardín paradisiaco que es Lima, por su devoción cristiana y sus virtudes, expuestas a lo largo del poema.

Ahora bien, como crónica rimada, Fundación y grandezas también aspira a enseñar latín y otros conocimientos propios de la educación humanista de su época. De allí que el lector encuentre notas marginales a cada paso del poema para explicar algunas de sus referencias clásicas, literarias, históricas o mitológicas. Reparando en ese aparato, típico de la poesía culta, se observa la plena vigencia de Luis de Góngora, el único poeta más o menos contemporáneo de Valdés que se encuentra referido dentro del poema, junto a un amplio catálogo de autores latinos, con Virgilio y su Eneida como la referencia más destacada. Otro aspecto atendible de las notas marginales es que sacan a relucir el carácter de Fundación y grandezas como poema sobre las Indias para un público europeo, ya que, junto a los contenidos eruditos ya mencionados, también se cuenta con notas informativas sobre la realidad americana. Generalmente, se aclaran términos de origen quechua como huaca o viracocha, así como topónimos que resultarían ajenos a un lector peninsular. Resulta interesante, asimismo, la nota que comenta los «agostos perpetuos» (cuarteta 360): «Esto se entiende de los agostos y mayos de Europa, porque acá [en el hemisferio sur] tenemos el mayo por setiembre, que es la primavera, y el agosto por diciembre, que es verano». Con notas como esa, el lector no deja de percibir el objetivo de exhibición de ingenio y erudición que perseguía el autor, tanto porque se trataba de un rasgo de calidad literaria como porque pretendía distinguirse, como criollo, llamando la atención sobre los saberes adquiridos frente a un público crítico.

Por todas las características que venimos apuntando, la edición de Fundación y grandezas supone una empresa difícil, por la envergadura de sus referencias coloniales (especialmente una pequeña historia de la Lima de los siglos XVI y XVII) y por la factura de la lengua hispanolatina en que está compuesto. Como editora, Martina Vinatea ha abrazado un criterio flexible, el más eficaz, para la transcripción del texto: respeta, en la medida de lo posible, las grafías de origen latino que singularizan el poema y constituyen su esencia, a la vez que enmienda lecturas que parecen provenir de errores de cajistas. Superada la fijación del texto, la editora realiza un notable trabajo de anotación filológica, aclarando referencias eruditas, filiando muchas alusiones presentes en las notas marginales, y explicando versos de pretendida oscuridad que constituirían buena parte del deleite de su lectura en el Siglo de Oro y la cifra de su mérito literario.

Finalmente, Fundación y grandezas de la muy noble y muy leal ciudad de los Reyes de Lima es un «juguete de la erudición», como lo denomina el prologuista de Valdés, que permite auscultar de cerca la memoria y la identidad de las élites criollas de fines del XVII. El poema entraña curiosidad como objeto estético y su lectura acrecienta nuestro conocimiento del vasto territorio de la poesía del Siglo de Oro y de aquel, más breve, del género hispanolatino. Más productiva aún resulta su lectura para el historiador, ya que el poema es rico en datos, acontecimientos y 
personajes del mundo hispánico de entonces. La esmerada edición de Martina Vinatea, quien nos guía por este auténtico laberinto barroco para el lector lego, vuelve accesible al lector de ahora este raro artefacto poético. 